$5-2020$

\title{
Reconsidering the Rationale for the Duration of Data Exclusivity
}

Jonathan Kimball

Srividhya Ragavan

Texas A\&M University School of Law, ragavan.sri@law.tamu.edu

Sophia Vegas

Follow this and additional works at: https://scholarship.law.tamu.edu/facscholar

Part of the Health Law and Policy Commons, and the Intellectual Property Law Commons

\section{Recommended Citation}

Jonathan Kimball, Srividhya Ragavan \& Sophia Vegas, Reconsidering the Rationale for the Duration of Data Exclusivity, 51 U. Pac. L. Rev. 525 (2020).

Available at: https://scholarship.law.tamu.edu/facscholar/1399

This Article is brought to you for free and open access by Texas A\&M Law Scholarship. It has been accepted for inclusion in Faculty Scholarship by an authorized administrator of Texas A\&M Law Scholarship. For more information, please contact aretteen@law.tamu.edu. 


\title{
Reconsidering the Rationale for the Duration of Data Exclusivity
}

\author{
Jonathan Kimball, Srividhya Ragavan \& Sophia Vegas*
}

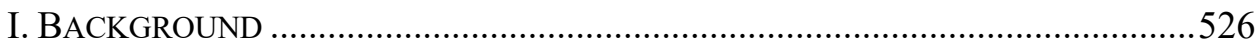

II. THE NATURE OF PHARMACEUTICAL EXCLUSIVITY ......................................527

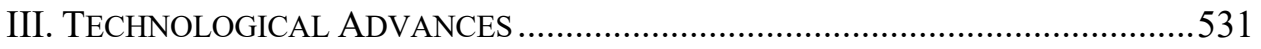

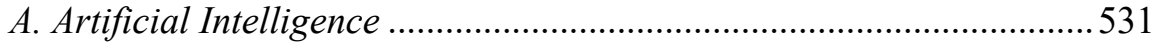

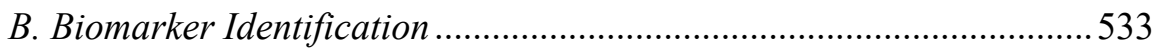

C. Patient-centered Mobile Technology ...............................................534

IV. TECHNOLOGICAL ADVANCEMENT \& IMPACT OF EXCLUSIVITY

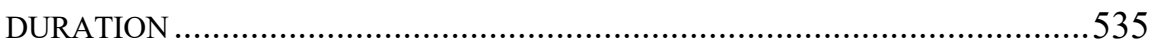

V. CONCLUSION ................................................................................... 536

2008 Headline: "Data exclusivity recognizes the substantial investment that innovators must make to develop the safety and efficacy data necessary to gain FDA regulatory approval." "

2019 Headline: Artificial intelligence and biomarkers change drug discovery, making it more efficient and less risky.

Machine learning and other technologies are expected to make the hunt for new pharmaceuticals quicker, cheaper and more effective. ${ }^{2}$

Given that technological advancement reduces the cost and the time for drug discovery and approval, the authors raise the issue of whether we still need the 12years of exclusivity ${ }^{3}$ that was needed in 2008 ?

* Jonathan Kimball is a Vice President for Trade and International Affairs at the Association for Accessible Medicines. Srividhya Ragavan is a Professor of Law at Texas A\&M School of Law; Sofia Vegas is a senior at Georgetown University and was an intern at the Association for Accessible Medicines when she worked on this paper.

1. Henri Grabowski, Follow-On Biologics: Data Exclusivity and the Balance Between Innovation and Competition, 7 NATURE REVS. Drug DisCOVERY 479, 479 (June 2008) (on file with The University of the Pacific Law Review).

2. Nic Fleming, Computer-Calculated Compounds, 557 NATURE S55, S55 (May 31, 2018) (on file with The University of the Pacific Review).

3. Compare Henri Grabowski, Follow-On Biologics: Data Exclusivity and the Balance Between Innovation and Competition, 7 NATURE Revs. Drug Discovery 479, 479 (June 2008) (on file with The University of the Pacific Law Review) (defining the term data exclusivity), with Nic Fleming, Computer-Calculated Compounds, 


\section{BACKGROUND}

One of the trickiest issues with drug development has been the balancing of costs and associated risks with the pricing of a drug. A good balance of these factors is essential to arrive at a price that incentivizes research without compromising on affordability of the medication. To compensate for the cost and risk associated with drug development, pharmaceutical companies enjoy government protections which allow them to maintain a monopoly over their products for an extended period of time. But, the balance between pricing and access has become so skewed in favor of the drug companies that the never-ending increasing costs of new life-saving medications raise questions about the basic assumptions on which the government built protections for the industry.

Governments provide data or market exclusivity to incentivize innovation. While in theory, the exclusivity period is commensurate with the expense of bringing a drug to the market, the cost of that research and development process remains a disputed factor. On the one hand, drug development is estimated to be a whopping \$2.7 billion, while others academic studies suggest at a more manageable $\$ 648$ million. ${ }^{4}$ It is also estimated that it takes at least six to seven years to go from initial discovery to the marketplace, wherein drugs undergo extensive clinical trials. ${ }^{5}$ Given this, the term of exclusivity — whether it be patent, data or market exclusivity-is structured to allow pharmaceutical companies to keep follow-on producers away from the market for a limited period of time. But, it is sometimes critical for follow-on producers to access this proprietary data in order to enter the market as soon as the period of patent exclusivity ends. For example, for small molecule drugs, the proprietary data developed by the original medicine producer is important for follow-on producers to file generic applications.

This paper focuses on the assumptions used to justify the current terms of data and market exclusivity. It is important to appreciate that the term of exclusivity does not change to accommodate varying periods of drug development. Such set terms do not recognize that drug development is not a stagnant science. Rather, it is a dynamic process that builds off gained knowledge and technological advancements and leads to innovations both significant and minor.

557 NAtURe S55, S55 (May 31, 2018) (on file with The University of the Pacific Law Review) (defining the term market exclusivity). The Flemings article makes the distinction as appropriate and highlights the distinctions where required.

4. Costs to Bring a Drug to Market Remain in Dispute, Managed Care (Sept. 14, 2017), https://www.managedcaremag.com/news/20170914/costs-bring-drug-market-remain-dispute (on file with The University of the Pacific Law Review).

5. John Walker, Machine Learning Drug Discovery Applications - Pfizer, Roche, GSK, and More, EMERJ (last updated Feb. 2, 2019), https://emerj.com/ai-sector-overviews/machine-learning-drug-discoveryapplications-pfizer-roche-gsk/ (on file with The University of the Pacific Law Review). 
Meanwhile, new and emerging technologies are being used to enhance efficiencies and reduce the time it takes to bring a drug to the market. As a result, pharmaceutical companies are able to not only launch products sooner but also run clinical trials more quickly and with less cost. Considering this, the Article asserts that as new technologies are adopted and advances in scientific understanding are leveraged resulting in shorter drug development timelines, it will be important to reduce the period of exclusivity granted to small molecule drugs and biologics.

After discussing the nature of pharmaceutical exclusivity, this Article highlights key technological changes and how those changes impact pharmaceutical research and development. Lastly, the Article discusses how both cost and efficiencies are improved from the use of technology, thus making the case for reducing the time period for protection of data exclusivity.

\section{THE NATURE OF PHARMACEUTICAL EXCLUSIVITY}

Pharmaceutical exclusivity is a period of protection - sometimes described as "market exclusivity" or "data exclusivity" depending on the scope and effect of the particular type of exclusivity granted by governments to pharmaceutical companies that results in delayed competition. The objective of this protection period is to compensate companies for the costs and risks associated with clinical trials and drug development. The term "data exclusivity" refers to statutory provisions that protect clinical trial data such that it results in prohibition of reliance on the submitted data towards approval or submission of abbreviated applications for generic versions of brand-name drug products. "Market exclusivity," a different type of protection, is the period when the regulatory body accepts applications for follow-on products, but does not grant approval, per se, which results in ensuring additional monopoly protections. Thus, data exclusivity essentially treats the data generated during clinical trials submitted to the United States Food and Drug Administration ("FDA") towards marketing approval agencies as exclusive to the organization/corporation that conducted the clinical trial; market exclusivity ensures that the original producer faces no competition from a follow-on product.

Operationally, the data exclusivity regime provides a layer of protection for the data gathered by innovator drug companies and operates outside the realm of patent protection. For innovator pharmaceuticals, protecting the clinical trial data provides an additional economic opportunity by creating a new market for the information relating to safety and efficacy of the drug. Such exclusivity may operationally help provide market exclusivity for compound(s) that may even fail patent scrutiny.

Currently, taking small molecule drugs as an example, the protection is for the data that the organization developed during the research process. This form of protection does not exclude generic competition de jure, presuming there is no active patent protection. However, it does provide de facto monopoly conditions, since there are very few instances when the company producing the follow-on 
product would choose to make the investment in clinical trials necessary to prove safety and efficacy. For the follow-on generic company, the preference would be to just wait until the data exclusivity period expires. Unlike patent protection, the period of data exclusivity is linked directly to the data of marketing approval. Entering the market after the expiration of data exclusivity is cost effective for the generic drug companies since, by not undertaking their own clinical research, generic drug companies are able to price their products more competitively.

For biologics, which are increasingly important (and expensive) options for patients living with cancer, autoimmune and other maladies, the exclusivity period is not only longer (12 vs. 5-7.5 years in the United States), but also provides a guaranteed market exclusivity period extending to 12 years. During the first four years of the 12-year period, the original reference brand product has both data exclusivity and market exclusivity, based on the pathway described in Section 351(k) of the Public Health Services Act. ${ }^{6}$ Specifically, data exclusivity is provided to the original biologic drug for four years, during which time the FDA cannot accept an application for a biosimilar product referencing that original product. Following the end of that four-year period and for an additional eight years, a biosimilar manufacturer can submit a marketing authorization application, but the FDA cannot approve that application, resulting in a combined 12 years of market exclusivity for the original biologic product. $^{7}$

Duke University professor Henry G. Grabowski had defended - and continues to defend ${ }^{8}$ - the 12-year exclusivity period for biologics. ${ }^{9}$ His study, published in 2008 with data from 2006 and earlier,(and paid for by the Pharmaceutical Research and Manufactures of America ("PhRMA")), found that "break-even lifetime for the portfolio occurs at 12.9 years .... This sensitivity reflects the lengthy research and development ("R\&D") investment periods associated with pharmaceutical and biopharmaceutical investments." " Professor Grabowski takes the example of bevacizumab (Avastin; Genentech/Roche), which is one of the first of a new class of drugs to treat colorectal cancer. The paper illustrates that in 1997, Genentech submitted information on bevacizumab, a workable antibody, to the FDA. Although Phase I of the clinical trials commenced the same year, the trial finally

\footnotetext{
6. See 42 U.S.C. $\S 262(\mathrm{k})$ (2017); Catherine Garza, Effects on Exclusivity: The Biologics Price Competition and Innovation Act of 2009, CAMARGO (Sept. 1, 2016), available at https:/camargopharma.com/resources/blog/effects-on-exclusivity-the-biologics-price-competition-andinnovation-act-of-2009 (on file with The University of the Pacific Law Review).

7. See 42 U.S.C. $\S 262(\mathrm{k})(2017)$.

8. Stephen Ezell et al., US Must Stand Up For Life-Sciences Innovation Provisions in the USMCA, HILL (June 6, 2019, 1:30 PM), available at https://thehill.com/opinion/international/447247-us-must-stand-up-for-lifesciences-innovation-provisions-in-the-usmca (on file with The University of the Pacific Law Review).

9. Henri Grabowski, Follow-On Biologics: Data Exclusivity and the Balance Between Innovation and Competition, 7 NATURE REVS. DRUG DisCOVERY 479, 479 (June 2008), https://www.nature.com/articles/nrd2532 (on file with The University of the Pacific Law Review).

10. Stephen Ezell et al., US Must Stand Up For Life-Sciences Innovation Provisions in the USMCA, HILL (June 6, 2019, 1:30 PM), available at https://thehill.com/opinion/international/447247-us-must-stand-up-for-lifesciences-innovation-provisions-in-the-usmca (on file with The University of the Pacific Law Review).
} 
ended in February 2004, allowing the FDA to approve bevacizumab as the first anti-angiogenic drug for treating cancer. While confirming that biologics overall had a better success rate than chemicals for approval, the study focuses on failure rates and probabilities of success as opposed to actual rates of success to arrive at the 12.9 years of exclusivity. Since its publication, this study has raised questions repeatedly, with critics challenging its premise that 12 years is necessary to incentivize the development of biosimilars. ${ }^{11}$ In fact, just recently, Nature Biotechnology found that "preclinical development times were not different between biologic and small-molecule drugs but were shorter for biologics." "12

The Grabowski argument is sometimes justified on the grounds that patents on biologics are not always granted and often are more susceptible to being invalidated. Hence, the wisdom is to bestow drug companies inordinate periods of exclusivity so they would not be discouraged from investing in research over biological substances. Others assert that "biotech products, like monoclonal antibodies, are very difficult for generic companies to develop and the absence of data exclusivity in a country would discourage the originator company from entering this market, which would have the deleterious effect of depriving people of the benefits of these drugs."13 Nevertheless, even Professor Grabowski highlights a red-flag that can potentially choke competition in adding that, "if data exclusivity periods are too long, price competition could be delayed beyond what is necessary to encourage innovation." 14

Two important changes comport with the red flags that Professor Grabowski raises and consequently, makes his analysis dated. First, new technology such as AI has contributed to shortening the time required for clinical trial such that the long period of exclusivity is not justified. Second, pharmaceutical companies have tended to seek additional periods of exclusivity such as through orphan designation or, pediatric exclusivity. ${ }^{15}$ For example, in the United States, in addition to the data and market exclusivity period awarded for NCEs, a pediatric exclusivity of 6 months,${ }^{16}$ which is a form of market exclusivity for the pediatric designation is

11. Zachary Brennan, New Study Questions the Need for 12 Years of Market Exclusivity for Biologics, REGULATORY FOCUS (June 21, 2019), available at https://www.raps.org/news-and-articles/newsarticles/2019/6/new-study-questions-the-need-for-12-years-of-marke (on file with The University of the Pacific Law Review).

12. Reed F. Beall et al., Pre-Market Development Times for Biologic Versus Small-Molecule Drugs, 37 NATURE BIOTECHNOLOGY 708, 709 (June 18, 2019), available at https://www.nature.com/articles/s41587-0190175-2.pdf (on file with The University of the Pacific Law Review).

13. Wael Armouti \& Mohammad F.A. Nsour, Data Exclusivity for Pharmaceuticals: Was It the Best Choice for Jordan Under the U.S.- Jordan Free Trade Agreement?, 17 OREGON REV. INT'L L. 258, 260 (2016), available at https://law.uoregon.edu/images/uploads/entries/Nsour.pdf (on file with The University of the Pacific Law Review).

14. Henri Grabowski, Follow-On Biologics: Data Exclusivity and the Balance Between Innovation and Competition, 7 NATURE REVS. DRUG DisCOVERY 479, 479 (June 2008), https://www.nature.com/articles/nrd2532 (on file with The University of the Pacific Law Review).

15. See Federal Food, Drug, and Cosmetic (FD\&C) Act of 1938 § 505(a), 21 U.S.C. § 355(a) (2012) (granting an additional 6-month period of exclusivity to the existing 12- and 4- year exclusivity periods).

16. See Federal Food, Drug, and Cosmetic (FD\&C) Act of 1938 § 505(a), 21 U.S.C. § 355(a) (2012) 
added to some existing drugs. This extension attaches at the end of term if the sponsor submits pediatric studies on the active moiety in response to a Written Request from FDA.

The real world experience of biologic producers demonstrates that exclusivity for biologics can be much longer than even the 12.9 years that Grabowski suggested. For an increasing number of approved biologics, a separate period of 7 years of exclusivity may be awarded under the Orphan Drugs Act for each use of the drug to treat an orphan condition. ${ }^{17}$ For the orphan indication, a biosimilar (section 351(k) of Public Health Services Act) product may not be licensed by the FDA until after the expiration of the 7-year orphan drug exclusivity period or the 12-year reference product exclusivity, whichever is later. Thus, if the product with a 12-year exclusivity gets approval for an orphan indication in its, say, 11th year, the biosimilar will benefit from 17 years of different forms of hybrid exclusivities. ${ }^{18}$ Recently, National Public Radio reported that more than 70 drugs) that were approved as Orphan Drugs were in fact familiar brand names which were strategically later approved as orphans - out of the 148 records the Government Accountability Office reviewed, $38.5 \%$ had been previously approved drugs. ${ }^{19}$ Such examples include popular mass market drugs, such as the cholesterol blockbuster Crestor, Abilify for psychiatric conditions, cancer drug Herceptin, and rheumatoid arthritis drug Humira, which is the best-selling medicine in the world (earning more than $\$ 19$ billion in 2018 alone). ${ }^{20}$ Each of these represent the reapproval of a mass marketed drug as an orphan drug when their patent was about to expire. In essence, the orphan status essentially enabled an additional seven years of exclusivity for a drug which already benefitted from patent protection as well as one layer of data and market exclusivity for treating another disease. This phenomenon is the red-flag that Grabowski himself highlighted, making a case for reduced term of protection.

Second, the use of artificial intelligence, biomarkers, patient-centered mobile technology, and other medical and technological advancements has improved drug candidate identification, patient participation in and engagement during clinical trials, and the overall likelihood of trial success. For example, in oncology, advanced analytics and the increased use of biomarkers have improved the ability to identify unique gene signatures and support the identification of clinical trial

(granting an additional 6-month period of exclusivity to the existing 12- and 4- year exclusivity periods).

17. FD\&C Act $\S 527(a)$.

18. FD\&C Act $\S 527(a)$. Andrew Bourgoin \& Beth Nuskey, An Outlook on US Biosimilar Competition White Paper, Thomson Reuters (April 2013), https://healthtrustpg.com/biosimilars/pdf/thomson-reuters.pdf.

19. Sarah J. Tribble, GAO Will Investigate Skyrocketing Prices For Orphan Drugs, NPR, March 22, 2017 https:/www.npr.org/sections/health-shots/2017/03/22/521081742/gao-will-investigate-skyrocketing-prices-fororphan-drugs; see also Sarah J. Tribble \& Sydney Lupkin, FDA Faulted for Lapses in Orphan Drug Program, NPR (Nov. 30, 2018), https:/www.npr.org/sections/health-shots/2018/11/30/672287029/fda-faulted-for-lapsesin-orphan-drug-program (on file with The University of the Pacific Law Review).

20. AbbVie Reports Full-Year and Fourth-Quarter 2018 Financial Results, ABBVIE (Jan. 25, 2019), available at https://news.abbvie.com/news/abbvie-reports-full-year-and-fourth-quarter-2018-financialresults.htm (on file with The University of the Pacific Law Review). 
participants at a faster rate and with greater precisions than previously. Considering these developments, IQVIA's Clinical Trial Trends Impact Assessment tool suggests that there will be a $104 \%$ and $71 \%$ increase in oncology R\&D productivity because of advanced analytics and biomarkers, respectively. ${ }^{21}$

Technological advancements such as these promise to significantly reduce the time between initial research and regulatory approval, increase the likelihood of trial success, while also reducing the cost of such trials. In doing so, they defy the logic behind the Grabowski analysis based on which the current terms of exclusivity are structured. That is, as these technologies are increasingly used in biopharmaceutical R\&D, the need for long periods of exclusivity is reduced. In fact, as technology advances and continues to increase efficiencies in drug development, the case for lengthy exclusivity periods weakens considerably.

\section{TECHNOLOGICAL ADVANCES}

This section identifies several technological advances that hold the promise of significantly reducing the time and risk involved in drug development. Specifically, we examine the impact of artificial intelligence, the increased use of biomarkers, and the growth in the use of patient centric mobile technology in clinical trials on drug development.

\section{A. Artificial Intelligence}

Artificial Intelligence can be used in multiple stages of the drug development process to reduce risk and minimize development time. First, AI can be used to analyze data to predict relationships between biological mechanisms and symptoms which can be useful for treatment, typifying and classifying patients, and for understanding side-effects. Second, AI can be immensely useful in the drug discovery stage. The IQVIA study mentions that, "when applied in the discovery field, AI may strengthen computational models that predict link between drug structure and activity/efficacy/safety (i.e. SAR) to improve success rates." 22 AI's ability to generate benefits has resulted in collaborative models that vastly improve the involved processes. For instance, Michael Devoy, the Chief Medical Officer of Bayer AG's Pharmaceutical Division noted that, "we are in active collaborations in the Cardiovascular and Oncology therapeutic areas with external partners (e.g., the BROAD institute) to achieve [better characterize and stratify disease and the

21. IQVIA INST. For HUM. DATA SCI., The ChANGING LANDSCAPE OF RESEARCh AND DEVELOPMENT: InNovation, Drivers of Change, and Evolution of Clinical Trial Productivity, 4 (Apr. 2019), available at https://www.healthindustryhub.com.au/wp-content/uploads/2019/05/the-changing-landscape-ofresearch-and-development.pdf (on file with The University of the Pacific Law Review).

22. IQVIA INST. FOR Hum. DATA SCI., The ChangING LANDSCAPE OF RESEARCH AND DEVElopment: InNovation, Drivers of Change, AND EVolution of Clinical Trial Productivity, 43, 58 (Apr. 2019), https://www.healthindustryhub.com.au/wp-content/uploads/2019/05/the-changing-landscape-of-research-anddevelopment.pdf (on file with The University of the Pacific Law Review). 
appropriate patient solutions]." 23 This type of cooperation is especially important in the early phase of drug discovery.

Once a drug is developed, AI helps improve and quicken the ability of drug companies to analyze the wealth of data. This includes data already created in past clinical trials, as well as new data that is being compiled internally by the company and externally through partners such as universities, government research institutes, and biobanks. In this arena, AI will lead to better and faster analysis of available data, generating new hypotheses to test clinically, speeding the enrollment by guiding patient identification, enabling precision to better detect treatment effectiveness, predicting which clinical sites are most likely to recruit and perform well, and enabling novel trial designs including adaptive trials. ${ }^{24}$

IQVIA, through its Clinical Development Productivity Index, predicts the percent change in clinical productivity driven by AI and predictive analytics to be $16 \%$ in 5 years. ${ }^{25}$ In turn, the expedited analysis will lead to the next benefit of using AI, which is accuracy. By allowing for candidates of specific drugs to be more accurately identified, AI can also decrease the time and cost of drug development and thus, improve efficiency. Merck KGaA's website substantiates this in stating that, "artificial intelligence is emerging as a pillar in the biopharmaceutical R\&D model, giving us exponential opportunity to complement our existing expertise with further speed and better precision. For patients, this could mean faster access to novel treatment options." ${ }^{26}$

AI has already proven to be more efficient in the scientific realm. DeepMind, a company of Google's parent company Alphabet Inc., uses AI for different types of scientific discovery. In 2018, DeepMind competed against scientists with high levels of expertise in drug development and proved itself more successful at predicting 3D structures of proteins in the CASP13 competition with its AI invention, AlphaFold. Accurate modeling of protein structures could speed up drug development. AlphaFold was able to determine the proteins with higher accuracy and faster pace the majority of the time when compared to highly experienced drug researchers. Evidently, as shown by DeepMind, AI has the potential to expedite

23. Michael Devoy, Artificial Intelligence: Technology Driven Prediction to Advance Patient Care, PHARMA.BAYER (Aug. 3, 2019), available at http://pharma.bayer.com/en/innovation-partnering/artificialintelligence-technology-driven-disease-prediction-to-advance-patient-care/ (on file with The University of the Pacific Law Review).

24. IQVIA INST. FOR Hum. DATA SCI., The Changing LANDSCAPE OF RESEARCH AND DEVElopment: InNovation, Drivers of Change, AND Evolution of Clinical Trial Productivity, 5 (Apr. 2019), available at https://www.healthindustryhub.com.au/wp-content/uploads/2019/05/the-changing-landscape-ofresearch-and-development.pdf (on file with The University of the Pacific Law Review).

25. IQVIA InSt. FOR Hum. Data SCI., The Changing Landscape of Research and DeVelopment: InNOVAtion, Drivers of Change, AND EVOlution of Clinical Trial Productivity, 43, 58 (Apr. 2019), available at https://www.healthindustryhub.com.au/wp-content/uploads/2019/05/the-changing-landscape-ofresearch-and-development.pdf (on file with The University of the Pacific Law Review).

26. Merck KGaA, Darmstadt, Germany, Announces Collaboration with Iktos for Generative Artificial Intelligence (AI) Technology, EMDGROUP (Mar. 14, 2019), https://www.emdgroup.com/en/news/collaborationwith-iktos-14-03-2019.html (on file with The University of the Pacific Law Review). 
and decrease the cost of drug development. For this reason, the success of AlphaFold's new AI machine brings high expectations to the future of drug development. ${ }^{27}$

In sum, almost all major pharma companies have significant projects with AI companies, as most recognize the role that AI can play in drug development. BenchSci reports that at least 33 pharmaceutical companies are engaged in $\mathrm{AI}^{28}$ Also, most are looking to stay ahead of the game and perfect their drug development process.

\section{B. Biomarker Identification}

Biomarkers are also changing the way drugs are developed and how they reach the market. A biomarker is "a characteristic that is objectively measured and evaluated as an indicator of normal biological processes, pathogenic processes, or pharmacologic responses to a therapeutic intervention." ${ }^{29}$ Biomarkers in clinical studies have been used for diagnosis and as "a tool for staging disease as indicators of disease status, and to predict and/or monitor clinical response to therapeutic intervention (e.g., electrocardiogram, PET brain image, serum chemistries, autoantigens $\mathrm{n}$ blood, bone densitometric measurement, pulmonary function test, neonatal Apgar score)." ${ }^{, 30}$ If used effectively, drug developers will be able to gain more insight into biomarkers themselves. This, in turn, will undoubtedly increase the probability of successful use of biomarkers for more accurate drug development and higher beneficial outcomes for patients.

As biomarkers become a staple of drug development and usage, the time it takes to create a drug will decrease, bringing down its costs as well. As noted by IQVIA, "[b]iomarkers will have the greatest impact on clinical productivity yielding a 34\% average increase [in productivity] across all phases of development." ${ }^{31}$ This is because during clinical development, biomarkers will alter patient eligibility criteria to a narrower population and decrease sample size, "add

27. Jeremy Kahn, Alphabet's DeepMind AI Algorithm Wins Protein-Folding Contest, BloomBerg (Dec. 2, 2018, 7:36 PM), https://www.bloomberg.com/news/articles/2018-12-03/alphabet-s-deepmind-ai-algorithmwins-protein-folding-contest (on file with The University of the Pacific Law Review).

28. Simon Smith, 33 Pharma Companies Using Artificial Intelligence in Drug Discovery, BENCHSCI. (Sept. 3, 2019), available at https://blog.benchsci.com/pharma-companies-using-artificial-intelligence-in-drugdiscovery (on file with The University of the Pacific Law Review).

29. See JK Aronson et al., Biomarkers and Surrogate Endpoints: Preferred Definitions and Conceptual Framework, NIH Biomarkers Definitions Working Group, 1998, BR J CLIN PHARMACOL 2005 May; 59(5): 49194, 491 (2005), available at https://www.ncbi.nlm.nih.gov/pmc/articles/PMC1884846/ (on file with The University of the Pacific Law Review).

30. Attila A. Seyhan, Biomarkers in Drug Discovery and Development, EUR. PHARM. REV. (Nov. 1, 2010), https://www.europeanpharmaceuticalreview.com/article/4357/biomarkers-drug-discovery-development/ (on file with The University of the Pacific Law Review).

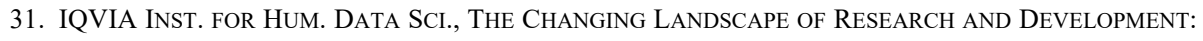
innovation, Drivers of Change, ANd Evolution of Clinical Trial Productivity, 58 (Apr. 2019), available at https://www.healthindustryhub.com.au/wp-content/uploads/2019/05/the-changing-landscape-ofresearch-and-development.pdf (on file with The University of the Pacific Law Review). 
new dimensions of genomic data access to trial recruitment," "strengthen drug efficacy signals and reduce side effects," "enable novel trials designs including basket trial designs," and "enable a shift to more standardized efficacy and safety endpoints among biomarkers related to therapeutic response." 32 The ability to target specific populations decreases the risk of drug development including the challenge of patient recruitment for trials. If this is the case, the drug development period will undoubtedly decrease, proving it no longer necessary to have such elevated exclusivities.

Biomarkers will allow pharmaceutical companies to work specifically on a patient-by-patient basis in order to determine drug prescriptions. As found by Attila Seyhan, "effective translation of the preclinical biomarkers into the clinic will pave the way towards effective execution of personalized therapies across complex disease areas for the benefit of patients, healthcare providers and the biopharmaceutical industry." 33 The increased use of biomarkers will help identify subgroups of patients susceptible to specific sub-variants of diseases and specific populations that will benefit from specific therapies.

\section{Patient-centered Mobile Technology}

The use of mobile technology by patients in clinical trials will also be beneficial for drug development. This technology allows increased feedback on a range of inputs that will help identify benefits and risks of a therapy as it moves through the development process, including in phase IV trials. This type of technological advancement is leading to better care for patients. Not only this, but it has also proven to be a great source of real-world data collection. The wealth of data that can be collected remotely and continuously also allows for increased use of adaptive trial design, increasing the potential for trial success.

Digital health and mobile technologies centered in patient input will "improve the capture of drug efficacy and safety data," "facilitate the collection of patientreported outcomes," "improve patient safety within a trial setting," "enable virtual patient visits and site-less trial formats," "improving patient experience," and "reduce trial management 'work burden' at clinical site and speed recruitment." 34 This will be facilitated by tools such as telemedicine and virtual physician visits, connected biometric sensors, consumer mobile apps, disease management apps,

32. IQVIA INST. For HUM. DATA SCI., The ChANGING LANDSCAPE OF RESEARCH AND DEVELOPMENT: INNOvation, Drivers of CHANGe, AND EVOlution of CliniCAL TRial Productivity, 47-48 (Apr. 2019), available at https://www.healthindustryhub.com.au/wp-content/uploads/2019/05/the-changing-landscape-ofresearch-and-development.pdf (on file with The University of the Pacific Law Review).

33. Attila A. Seyhan, Biomarkers in Drug Discovery and Development, EuR. PHARM. REV. (Nov. 1, 2010), https://www.europeanpharmaceuticalreview.com/article/4357/biomarkers-drug-discovery-development/ (on file with The University of the Pacific Law Review).

34. IQVia Inst. For Hum. Data SCI., The Changing Landscape of Research and Development: innovation, Drivers of Change, AND Evolution of CliniCAl Trial Productivity, 35-36 (Apr. 2019), available at https://www.healthindustryhub.com.au/wp-content/uploads/2019/05/the-changing-landscape-ofresearch-and-development.pdf (on file with The University of the Pacific Law Review). 
consumer wearables, in-home connected virtual assessments, and web-based interactive programs.

Different uses of patient-centric technology will benefit the drug development process. As mentioned by Ronak Savla, scientific affairs manager at Catalent Pharma Solutions, "whilst the need for patient centricity has always existed, the focus on it has never been greater. Every dose design decision during development has the potential to influence patient outcomes. Besides safety and efficacy, patient-centricity should be the foundation of creating target product profile." ${ }^{\prime 35}$ As pharmaceutical producers continue to integrate patient-centered technology in their drug development, the efficiency and accuracy of medicines will exponentially grow.

The IQVIA Clinical Development Productivity Index found that patientcentered mobile technologies and the real-world data they help capture will have a $13 \%$ and $12 \%$ clinical productivity increase, respectively. ${ }^{36}$ This technology will also be beneficial for the later stages of development and drug approval. As stated by PhRMA, "advancing science-based approaches to collect robust and meaningful patient and caregiver input can more consistently inform drug development and regulatory decision making." 37 The continued advancement of this type of care, will decrease drug development time and increase its accuracy and quality, thus pointing, once again, to the inefficiency of elevated exclusivity periods.

\section{TECHNOLOGICAL ADVANCEMENT \& IMPACT OF EXCLUSIVITY DURATION}

From manufacturing to services to research and development, artificial intelligence, mobile technology, expansive scientific understanding, and other technologic advances have created economic efficiencies that drive down both the cost and the time it takes to develop a wide range of new consumer and industrial products. Biopharmaceutical research and development is no different. Technological advancements are becoming a game changer for drug development. As the above discussion highlights, they are creating an environment for more efficient research and development, with a reduction in both risk and development times.

Technology helps by better predicting the likelihood of toxicity in the earliest

35. Felicity Thomas, Patient-Centric Drug Development Comes of Age, 43 PHARM. TECH. 16-21 (Apr. 2, 2019), http://www.pharmtech.com/patient-centric-drug-development-comes-age?pageID=3 (on file with The University of the Pacific Law Review).

36. IQVIA InSt. FOR Hum. Data SCI., The Changing Landscape of Research and DeVelopment: InNovation, Drivers of Change, AND EVolution of Clinical Trial Productivity, 58 (Apr. 2019), available at https://www.healthindustryhub.com.au/wp-content/uploads/2019/05/the-changing-landscape-ofresearch-and-development.pdf (on file with The University of the Pacific Law Review).

37. PhRMA, Patient Focused Drug Development 2 (June 9, 2016), available at https://www.phrma.org//media/Project/PhRMA/PhRMA-Org/PhRMA-Org/PDF/patient-focused-drug-development.pdf (on file with The University of the Pacific Law Review). 
stages before a company even tries to take a drug to clinical trials. That would directly save the company money and time. For example, Pfizer collaborates with IBM to use Watson for drug discovery. IBM points out the average human researcher reads between 200 and 300 science articles a year while Watson has "ingested 25 million Medline abstracts, more than 1 million full-text medical journal articles, 4 million patents and is regularly updated." 38 The depth of knowledge that is created in such a short time can possibly enable machines to determine non-obvious connections that could lead to combination medicines for cancer. ${ }^{39}$ Similarly, Andrew Hopkins, the CEO of Exscientia, noted that, compared to traditional methods, Exscientia's system can deliver drug candidates roughly 25 percent faster and 25 percent cheaper. The algorithms can design new molecules and is intended to be able to better predict which molecules would be the most effective and safest. ${ }^{40}$

The costs and efficiencies presented by these technological advances make the argument for 12 years in the Grabowski article outdated. The assumption that 12 years of exclusivity will always be needed-or, as indicated in the Nature Biotechnology study noted above, is currently needed - is false and lacks basis. In fact, as new technologies are adopted into the drug discovery process, and their related efficiencies are captured, exclusivity periods should be reduced. It is time to recognize that pharmaceutical policies, designed to incentive drug development, must be dynamic, adapting to the pace and reduced risk that is drug development today.

\section{CONCLUSION}

The nature of drug development continues to evolve as technological advancements become more integrated into product development. The use of artificial intelligence, biomarkers and patient-centered mobile technology have proven and will continue to prove themselves successful in expediting the development of a single drug. Therefore, as pharmaceutical companies continue to integrate these into their development process, the time it will take them to develop new drugs will undoubtably decrease. The shorter development time will lead to less expensive medicines. This will mean that 12 -year market exclusivity periods currently protecting biologics from competition will increasingly be less relevant for compensating for the time it takes to develop a drug.

38. Jessica Bartlett, Pfizer to Use IBM Watson Supercomputing to Find New Drugs, Boston BusinEss JOURNAL (Dec. 1, 2016), available at https://www.bizjournals.com/boston/news/2016/12/01/pfizer-to-use-ibmwatson-supercomputing-to-find.html (on file with The University of the Pacific Law Review).

39. John Walker, Machine Learning Drug Discovery Applications - Pfizer, Roche, GSK, and More, EMERJ (Feb. 2, 2019), https://emerj.com/ai-sector-overviews/machine-learning-drug-discovery-applications-pfizerroche-gsk/ (on file with The University of the Pacific Law Review).

40. John Walker, Machine Learning Drug Discovery Applications - Pfizer, Roche, GSK, and More, EMERJ (Feb. 2, 2019), https://emerj.com/ai-sector-overviews/machine-learning-drug-discovery-applications-pfizerroche-gsk/ (on file with The University of the Pacific Law Review). 
As technological advances improve the success of drug development, and do so in less time than it has traditionally taken to develop a drug, the rationale for long periods of exclusivity will be decreased. Such a reduction will benefit healthcare systems, payers, patients, and, if it reflects increased certainty and less risk, the pharmaceutical industry as well. 